\title{
Effective Activities to Improve Consciousness in Satoyama Environmental Learning Which is Applied Blended Learning to as a Part of Teacher Education
}

\author{
Isao Miyaji ${ }^{1}$, Hirokazu Fukui ${ }^{2}$ \\ Former Professor in Okayama University of Science ${ }^{1}$, Shujitsu University ${ }^{2}$, Japan
}

\begin{abstract}
Lessons on satoyama environmental education were held for undergraduate students who are training to be educators. The lessons blend inquirybased learning through research using ICT tools and experiential learning in a complementary manner. Students learn about the underlying concepts about the environment from a global perspective through inquiry-based learning; experiential learning can encourage students to get involved with the environment at the local level and also develop abilities and skills to conduct classes in environmental education. This paper investigated which activities in the lessons were effective in improving their consciousness related to abilities. With consciousness of abilities listed in the rows and activities listed in the column, responses of students are created as a cross-tabulation table. Cluster analysis is conducted for the table to find some ability clusters and some activity clusters. Using table constructed by ability and activity cluster, $\chi^{2}$ test and residual analysis show activities effective for improving abilities. The results show activities effective for improving abilities. Results of significance testing for mean increase in scores of consciousness related to abilities are also shown.
\end{abstract}

\section{Introduction}

With a recent social economy change, it becomes difficult to maintain and manage natural environments full of changes peculiar to satochi and satoyama, and the blessing that come there, and in addition rich biological diversity [15].

Satoyama and satochi are the mountains and the lands at the interface of nature and human settlement. This was a finding reported in a survey of organizations which promote the preservation of satoyama. There have been attempts to improve the situation through educational programs with a heavy focus on experiential learning. E.g. In collaboration with an elementary school, the students were taught about the origins of satoyama and the health of the forests within it. They made continuous observations of the forest and spent time immersing in the forest environment. After which, the students then made recommendations to renegotiate the relationship between forests and humans for modern society [4].
As education to cultivate leaders for a sustainable society, UNESCO has been promoting Education on Sustainable Development (ESD) [9]. ESD aims to encourage students to catch global problem as own problem and to address the issues at hand at the community level. This brings new sense of values and action to be connected for problem solution. While this philosophy is widely known, the implementation of ESD currently is far from ideal. Therefore the practice method is still suggested now. For example, Nakaguchi et al. proposed experiential learning of satoyama and satoumi: the part of the ocean environment where humans and nature interact [14]. The dilemma faced was that: Studying the earth's environment requires a deep understanding of science and hence, exploration of this topic may end up being a paper exercise on theory and concepts. However, fieldwork can cause one to be myopic so as to focus too much on the activities at hand, and incur the risk of losing sight of the bigger picture.

Finding a balance between intellectual exploration and experiential learning is difficult. Most practice tends to focus on one at the expense of the other. René Dubos advocated the ideal of "Think globally, act locally" at the UN Conference on the Human Environment in 1972. The philosophy of ESD that UNESCO is promoting is based on this maxim. Environmental education resonates with the model which refers to the environment in a holistic, humanoriented approach as interacting biophysical, social, economic and political dimensions [6] Uyanık reported that considering nature walking activity's positive effect on study group's emotions towards environment, nature-based activities will be very beneficial for environmental education applications. Additionally, self-evaluation activities let students make assessment about themselves. Such a kind of activities can be used in order to let students develop awareness themselves [19]. Edsand \& Broich found some statistical evidence that environmental education can promote a higher level of environmental consciousness [2]. El-Batri, et al. reported that extracurricular environmental activities in Moroccan middle schools promoted effective environmental education [3].

A survey conducted previously shed light on how children interact with nature during daycare. This 
survey also presented concrete suggestions from nursery schools for nursery teacher training school in order to be effective [10]. Then a problem on promoting natural environmental education was considered. In another example, Ida, et al. conducted a survey about views in familiar nature and nature education accordingly for students in university for training teachers [8]. The survey found that the natural experience of the teacher own which supports children decreases [16]. It is thus vital to include interactions with nature as part of the curriculum for students in university for training teachers. To further promote environmental education, concrete evidence on the effectiveness environmental education is essential. Unfortunately, there are almost no attempts to collect and evaluate data in this area. Students in university for training teachers hold the key to the education of young children who will become our future leaders. Getting students in university for training teachers to understand the importance of evaluations is thus critical. Currently, there are no theses which have reported to measure and analyze the effectiveness of education programs on the natural environment for students in university for training teachers.

To realize Dubos' vision, this paper focuses on "blended learning" (BL), a teaching method that accommodates both inquiry-based learning and experiential learning. BL combines traditional classroom-based instruction, in which students go through similar learning experiences in the same time and space, with e-learning done on an individual basis. It is hoped that the two learning methods can complement each other to raise the overall learning effectiveness [11]. In one example, Fujimoto et al. observed that critical communication skills were fostered in elementary school students when they share their observations on flowering plants on electronic bulletin boards [5]. A class which combines e-learning and other media with a lecture is at present called a blended class [18]. It is possible to support many and various student learning styles and to deepen understanding by using more than one medium [1]. In this example, the increase in the consciousness of issues is significant through the BL method. The blended learning environment presented rich content, easy accessibility, effective guidance and motivation [20]. Beyond elementary and junior high schools, BL has proven to be effective in different contexts including early discovery of poor performers in class [7], acquisition of techniques in nursing school [17], ITrelated classes in higher education [12], student guidance, special education etc.

There are no precedent studies on the effect of conducting classes on environmental education about satoyama on trainee teachers using the BL method. In order to better fulfil Dubos' vision, BL which combines inquiry-based learning and experiential learning, will be the teaching methodology adopted in this study on the effect of environmental education on satoyama. Learning effects in this teacher education on satoyama environmental learning has been reported already [13]. The purpose of this paper is to know reasons that this learning shows effects by revealing activities effective for improving abilities. Responses of students were analyzed using cluster analysis. As a result, abilities are divided four clusters and activities are divided three clusters. After summing up the frequencies for each cluster, a 4 by 3 table can be drawn up. Using this table, $\chi^{2}$ test is performed. In the last time, a residual analysis is performed. The results show activities effective for improving abilities. It is shown that results of significance testing for mean increase in scores of consciousness related to abilities.

\section{Class Practice and Study}

\subsection{Class practice}

In the class, the space, method and media for conducting environmental education were modified to suit the contents to be covered in the BL-style environmental education on satoyama. It is hoped that the BL method helps to increase knowledge, cultivate practical skills and to increase the desire to do more for environmental education in the students. As part of the lessons, student research on the earth's natural environment using ICT tools. The knowledge gained and the critical thinking and decision-making skills fostered would help them develop a global perspective. On the other hand, efforts were also made to cultivate interest and desire in the students to interact with their surrounding environment, and to gain practical skills to protect the environment. This process would develop the local perspective in students.

The subject for the BL-style class is third-year trainee elementary school teachers who are taking the elective module "Science II". This module covers the theories on the various aspects of science education and the foundation of safety instruction in science. Six lessons of this module are dedicated to fieldwork on outdoor activities and environmental education. The six lessons are usually done through experiential learning in the university learning forest. The numbers (1)-(6) refer to the number of lessons held. For the class, all students learn about the theories of environmental education simultaneously through a lecture in lesson (1). In lessons (2), (3) and (4), basic skills on ensuring safety in outdoor activities and conducting vegetation survey are taught in groups. In lesson (5), students conduct their own research on environmental problems, an inquiry-based individual learning approach. Students then present their findings to each other in lesson (6) in their own groups, thus group learning occurs in 
this lesson. To investigate the effects of the class, pre- and post-surveys are conducted with the trainee teachers outside class time. The total number of trainees who took part in this module is 22 .

The sites for learning and teaching methods are illustrated in Figure 1. The lessons are conducted through the following ways: a lecture using a textbook, group instruction on practical skills by forestry experts, individual research using ICT equipment such as computers and smartphones, and group learning through presentations. BL occurs over three types of spaces (classroom, satoyama and students' own homes), through three learning methods (lecture in a classroom, group learning and individual learning), and through three forms of media (textbook, experts and ICT), with each space, method and media chosen to suit to the objectives of each lesson.

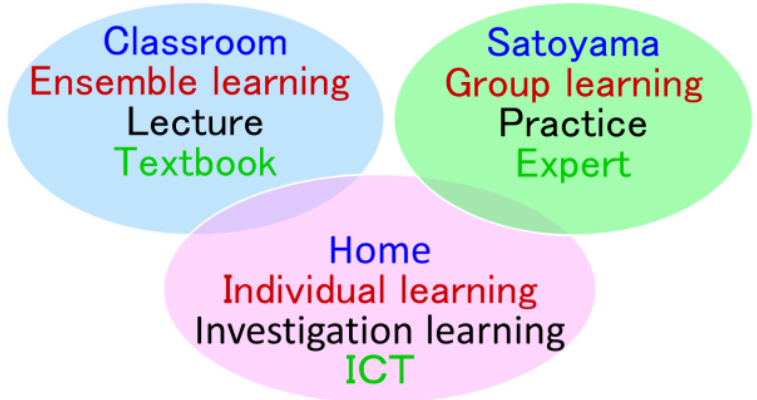

Figure 1. Blended Learning over three types of learning spaces, three types of learning methods and three types of media

\subsection{Survey method}

To find out if learning effectiveness is increased through a blend of learning spaces, methods and media, two types of survey questionnaires were designed.

Pre-surveys were held on November. The postsurvey held on December 14 consisted of 3 parts (1)(3) in pre-survey and an additional part on (4) activities that were perceived to be effective in improving abilities. A total of 22 students took this module. All of them were present for the surveys and all responses were used in the analysis.

(1) Recognition of technical terms associated with satoyama environmental education

(2) Confidence and desire to engage in environmental education

(3) Awareness of own abilities and improvement due to the class

(4) Activities which were effective in improving abilities

For each of the ability asked in (3), respondents were also asked that they felt which activities among the list of 30 activities contributed to the improvement in the ability as shown in Figure 2. The list of 30 activities is shown in Figure 3 and Table 1. Multiple responses are allowed.

\section{Analysis of Survey Results}

The following four types of analysis were conducted using the survey data.
[Analysis I] Clustering of (4) abilities that were perceived to have improved by activities that are effective by cluster analysis

[Analysis II] Clustering of activities by the frequency with which they contributed to (4) the consciousness of abilities improved by cluster analysis

[Analysis III] $\chi^{2}$ test and residual analysis to see which activity cluster contributed to the change in consciousness of ability cluster

[Analysis IV] Significance testing for mean increase in scores of consciousness cluster related to abilities.

For significance testing, the significance level of $5 \%$ is adopted. Significance levels of $0.1 \%, 1 \%$, and $5 \%$ are represented by $* * *, * *$, and $*$ respectively.

\subsection{Clustering of abilities that were perceived to have improved by activities that are effective}

Cluster analysis is performed to cluster abilities that were perceived to have improved on post-survey by the number of activities that contributed to the improvement. Results are as follows.

Table 1 shows results of survey (4), with the 30 items on consciousness of abilities listed on the left and the 30 activities which were effective in improving each of these abilities on the top row. Multiple answers are allowed. The numbers in brackets are the item numbers for the consciousness on abilities in the survey questionnaire, while the non-bracketed numbers refer to the item numbers for activities in the survey questionnaire. For each 
ability, the number of activities which contributed to its improvement was tallied. With 30 items on consciousness of abilities listed in the rows and 30 items of activities listed in the column, a 30 by 30 cross-tabulation table is created. The sum of the tally of activities identified to be helpful in improving each ability is 1,688. Using Ward's method, cluster analysis is performed with of abilities as cases and activities as the dependent variable. As a result, the dendrogram is obtained. The horizontal axis is the degree of dissimilarity and the vertical axis is the consciousness. When the degree of dissimilarity is about 12 in the dendrogram as shown in Figure 2, the abilities can be grouped into four clusters, I-IV.

Cluster I consists of 13 items from the consciousness of abilities as shown in Table 1 . Among these 13 items, item (30) on "Interest and concern about environmental education", item (24) on "sense of fulfilment and satisfaction" and item (25) on "Sense of accomplishment and achievement" have higher frequencies. As a result, cluster I is named as "Consciousness related to interest in and satisfaction of activities".

Cluster II consists of two items-item (16) "Ability to listen and ask questions" and item (19) Ability to appropriately evaluate thoughts of other people. As a result, cluster II is named "Consciousness related to abilities to listen and evaluate".

Cluster III consists of six items. Among the six items, item (8) "Ability to study by oneself and to learn" and item (21) "Ability to pursue and explore matters deeply" have higher frequencies. Hence, this cluster is named "Consciousness related to abilities to learn and explore".

Cluster IV consists of nine items. Among the nine items, item (15) "Ability to give presentations" and item (4) "Ability to broaden usage and situations of computers" have higher frequencies. Hence, this cluster is named "Consciousness related to computer and abilities to present".

(24) Sense of fulfilment and satisfaction

(25) Sense of accomplishment and achievement

(30) Interest in and curiosity about this field

(17) Communication ability

(23) Ability to cooperate and to learn concertedly

(7) Cultivation of understanding of knowledge learned

(20) Ability to correct and improve on one's own thoughts

(5) Ability to set challenges, ability to discover problems

(18) Ability to appropriately self-evaluate one's thoughts

(28) Ability to think, consider and come up with ideas by oneself

(29) Creativity/ability to create

(22) Ability to execute, ability to practice, ability to put into action

(6) Ability to plan, to do things in a planned manner

(16) Ability to listen and to ask questions

(19) Ability to appropriately evaluate thoughts of other people

(11) Ability to analyse information

(27) Ability to construct and create knowledge

(21) Ability to pursue and explore matters deeply

(26) Ability to solve problems

(8) Ability to study by oneself and to learn

(9) Ability to gather information, ability to conduct research

(2) Understanding of computers

(3) Computer operation skills

(4) Abikity to broaden usage and situations of computers

(1) Interest in and curiosity about computers

(14) Ability to talk to and explain to others comprehensively

(15) Ability to give presentations

(10) Ability to sort through related information or data

(12) Ability to express thoughts in writing

(13) Ability to express thoughts through media other than writing

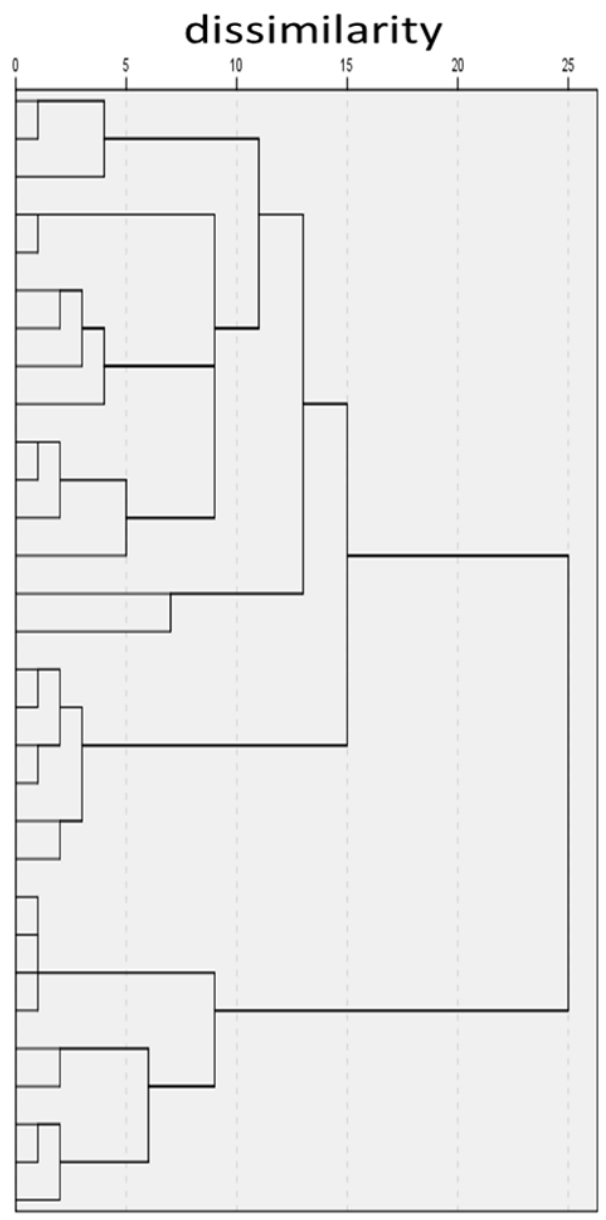

Figure 2. Dendrogram of abilities clusters determined using cluster analysis 
Table 1. Cross table and clustering of consciousness by activities

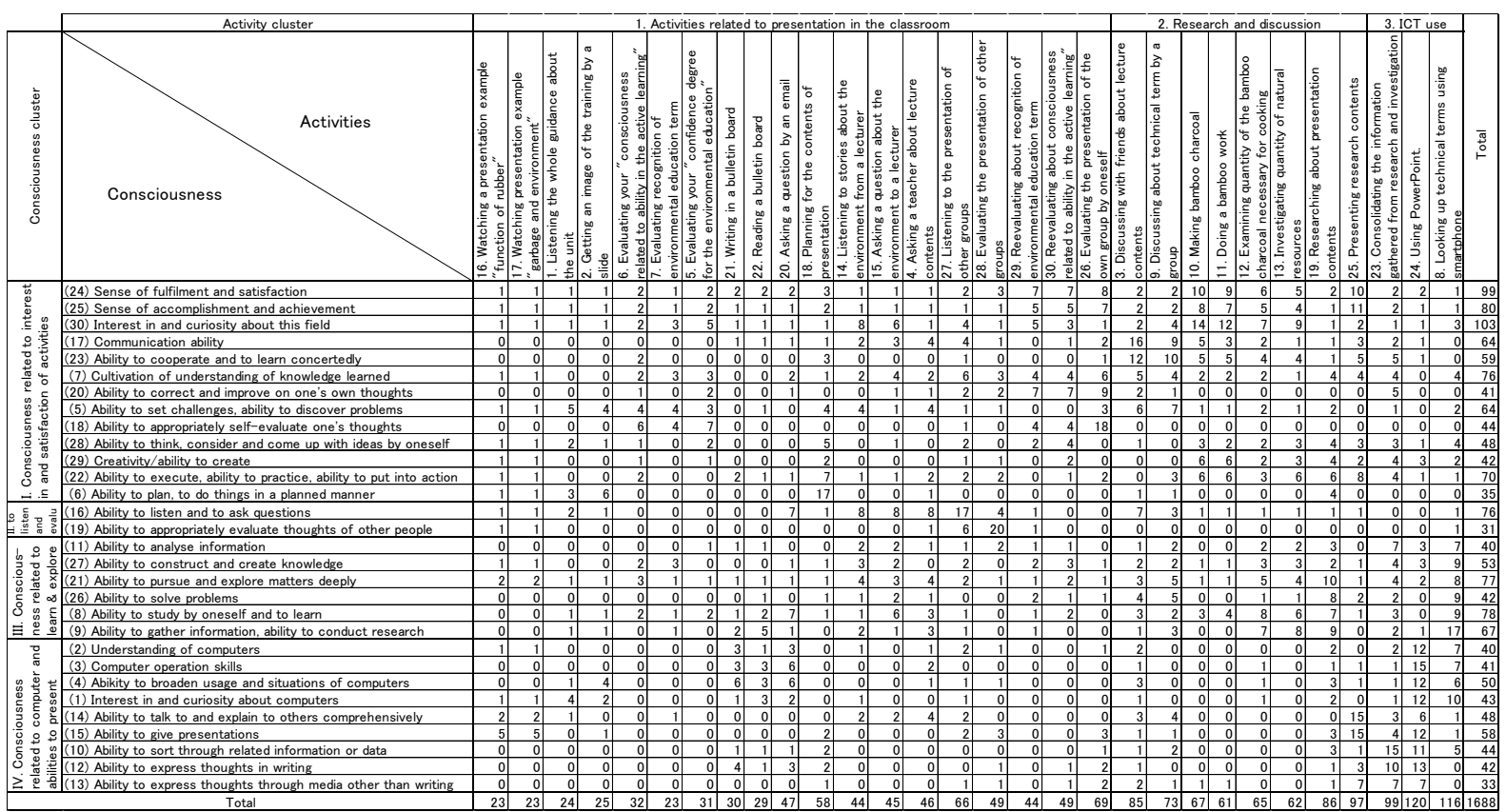

\subsection{Clustering of activities by the frequency with which they contributed to the consciousness of improvement in abilities}

Using Ward's method, cluster analysis is performed with activities as cases and consciousness of abilities as dependent variables using the cross table. As a result, the dendrogram is obtained. When the degree of dissimilarity is about 15 in the dendrogram as shown in Figure 3, the activities can be grouped into three clusters, 1-3.

Cluster 1 consists of 19 items. Among these, item 26 "Evaluating the presentation of the own group by oneself", item 27 on "Listening to the presentation of other groups" and so on have higher frequencies. As a result, cluster 1 is named as "Activities related to presentation in the classroom".

Cluster 2 consists of eight items. Among these, item 25 "Presenting research contents", item 19 "Researching about presentation contents", item 3 "Discussing with friends about lecture contents" and item 9 "Discussing about technical terms by a group" etc. have higher frequencies. As a result, cluster 2 is named "Activities related to research and discussion".

Cluster 3 consists of three items, namely item 24 "Using PowerPoint", item 8 "Looking up technical terms using smartphone" and item 23 "Consolidating the information gathered from research and investigation". Hence, this cluster 3 is named "Activities related to ICT use".

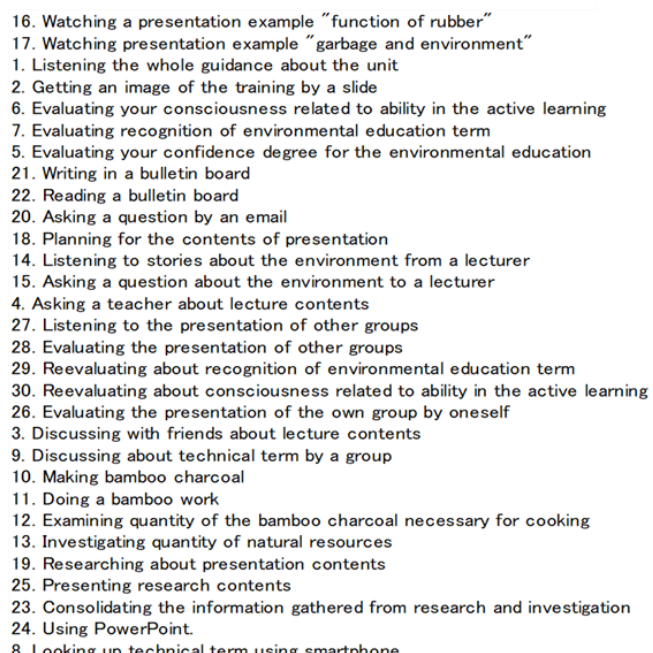

Figure 3. Dendrogram of activity clusters determined using cluster analysis

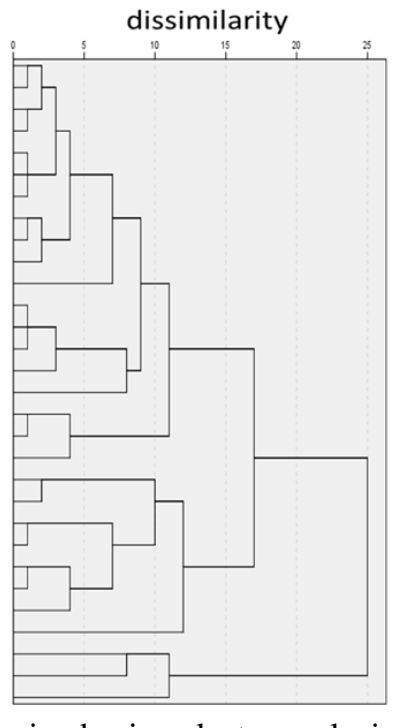




\subsection{Analysis of activities which are effective in improving abilities as perceived}

Crossing abilities that were perceived to have improved with the effective activities would have produced a 30 by 30 table. With the analysis as described in 3.1 and 3.2, the items can be rearranged according to the dendrogram as shown in Figures 2 and 3. After summing up the frequencies for each cluster, a 4 by 3 table can be drawn up. Using this table, $\chi^{2}$ test is performed. As a result, the observed frequencies are not evenly distributed, $\chi^{2}(6)=$ $322.8, \mathrm{p}<.001$. The next step is to perform a residual analysis. The results are shown on the bottom left of Table 2 in the column on adjusted residuals. For cells that contain results that bias show significance, cells with positive adjusted residuals correspond with the cells which have higher than expected frequencies. These cells are marked with asterisks as seem at the right bottom corner of Table 2 .

From the results, it is evident that students perceived that cluster 1 on "Activities related to presentation in the classroom" is effective for improving the abilities in cluster I "Consciousness related to interest in and satisfaction of activities" and cluster II "Consciousness related to ability to listen and evaluate". Students also felt that cluster 2 "Activities related to research and discussion" were effective in raising "Consciousness related to interest in and satisfaction of activities" (cluster I). Activities related to ICT use were perceived to be effective in improving "Consciousness related to learn and explore" (cluster III) and the "Consciousness related to computer and to present" (cluster IV).

From these results, we can conclude that the combination of three types of learning spaces and three types of learning methods with various types of media for classes on environmental education on satoyama is effective. Different abilities are improved in different learning situations; activities that support intellectual exploration and activities that support experiential learning complement each other to improve abilities as perceived by the students.

Table 2. Results of chi-squared test and adjusted residuals based on the cross table of consciousness cluster and activity cluster

\begin{tabular}{|c|c|c|c|c|c|c|c|}
\hline \multirow[b]{2}{*}{ Activity Cluster } & \multicolumn{4}{|c|}{ Observed frequency } & \multicolumn{3}{|c|}{ Expected frequency } \\
\hline & 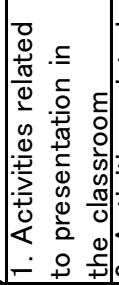 & 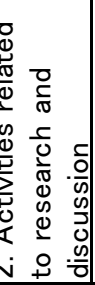 & 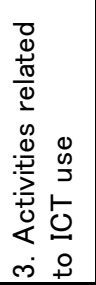 & $\begin{array}{l}\bar{\pi} \\
\stackrel{0}{0} \\
\vdash\end{array}$ & 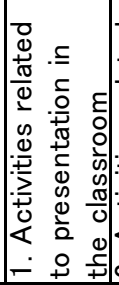 & 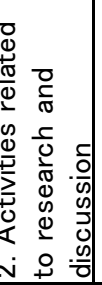 & 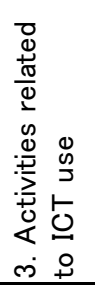 \\
\hline $\begin{array}{l}\text { I. Consciousness related to interest } \\
\text { in and satisfaction of activities }\end{array}$ & 408 & 355 & 62 & 825 & 370.0 & 291.3 & 163.7 \\
\hline $\begin{array}{l}\text { II. Consciousness related to abilities } \\
\text { to listen and evaluate }\end{array}$ & 89 & 16 & 2 & 107 & 48.0 & 37.8 & 21.2 \\
\hline $\begin{array}{l}\text { III. Consciousness related to abilities } \\
\text { to learn and explore }\end{array}$ & 129 & 138 & 90 & 357 & 160.1 & 126.0 & 70.9 \\
\hline $\begin{array}{l}\text { IV. Consciousness related to } \\
\text { computer and abilities to present }\end{array}$ & 131 & 87 & 181 & 399 & 178.9 & 140.9 & 79.2 \\
\hline Total & 757 & 596 & 335 & 1688 & 757.0 & 596.0 & 335.0 \\
\hline & \multicolumn{3}{|c|}{ Adjusted residual } & & \multicolumn{3}{|c|}{ Significance probability } \\
\hline $\begin{array}{l}\text { I. Consciousness related to interest } \\
\text { in and satisfaction of activities }\end{array}$ & 3.7 & 6.5 & -12.4 & & $* * *$ & $* * *$ & \\
\hline $\begin{array}{l}\text { II. Consciousness related to abilities } \\
\text { to listen and evaluate }\end{array}$ & 8.2 & -4.6 & -4.8 & & $* * *$ & & \\
\hline $\begin{array}{l}\text { III. Consciousness related to abilities } \\
\text { to learn and explore }\end{array}$ & -3.7 & 1.5 & 2.9 & & & & ** \\
\hline $\begin{array}{l}\text { IV. Consciousness related to } \\
\text { computer and abilities to present }\end{array}$ & -5.5 & -6.5 & 14.6 & & & & $* * *$ \\
\hline
\end{tabular}




\subsection{Significance testing of mean increase in scores of consciousness cluster related to abilities}

Paired t-test is performed on each of the four ability clusters to see if the mean increase in scores on the consciousness cluster of abilities is significant. The results are shown in Table 3. It demonstrates that all four clusters showed a significant increase on post-survey.

Next, analysis of variance was performed to see if there are any significant differences in the mean increases between the four clusters. The results were not significant, $\mathrm{F}(3,656)=1.07, \mathrm{p}>.05$. There are no significant differences in the mean increase across the consciousness of abilities in the four clusters.

Table 3. Mean increase, standard variation and results of t-test on the four ability clusters

\begin{tabular}{|l|c|c|c|c|}
\hline \multicolumn{1}{|c|}{ Consciousness Cluster } & $\mathrm{m}$ & $\mathrm{SD}$ & $\mathrm{t}$ & $\mathrm{p}$ \\
\hline I. Consciousness related to interest in and satisfaction of activities & 1.2 & 1.7 & 11.7 & $* * *$ \\
\hline II. Consciousness related to abilities to listen and evaluate & 0.8 & 1.2 & 4.0 & $* * *$ \\
\hline III. Consciousness related to abilities to learn and explore & 1.1 & 1.5 & 8.3 & $* * *$ \\
\hline IV. Consciousness related to computer and abilities to present & 1.2 & 1.6 & 10.7 & $* * *$ \\
\hline
\end{tabular}

\section{Discussion and Consideration}

\subsection{On analysis of activities which are effective in improving abilities as perceived}

Analysis has shown that the cluster 1 "Activities related to presentation in the classroom" is perceived to be effective in improving the scores of cluster I "Consciousness related to interest in and satisfaction of activities" and cluster II "Consciousness of abilities related to abilities to listen and evaluate". Cluster 2 "Activities related to research and discussion" is perceived to be effective in improving the scores of cluster I "Consciousness related to interest in and the satisfaction of activities". Cluster 3 on "Activities related to ICT use" is perceived to be effective in improving cluster III "Consciousness related to abilities to learn and to explore" and cluster IV "Consciousness related to computer and abilities to present". From these findings, it can be concluded that by employing the use of different spaces, learning methods and media environmental education on satoyama is effective in allowing for different abilities to be developed at different scenes, with intellectual exploration and experiential learning complementing each other.

From Table 2, it can be seen that objectives of cluster I "Consciousness related to interest in and the satisfaction of activities" can be achieved with either cluster 1 "Activities related to presentation in the classroom" or cluster 2 "Activities related to research and discussion". However, the data can also be interpreted in such a way that with only one group of activities, the "interest and satisfaction" felt by the students may not have been so high.

\subsection{On significance testing of mean increase in scores of consciousness cluster related to abilities}

All four clusters of abilities were significant for the mean increase in scores on all consciousness which belongs to each of the four ability clusters. Almost items had significant increased [13]. This means that results for scores of the consciousness which was collected into each cluster are same as result for score of each item.

In addition, it was shown that there was not a significant difference between the mean scores of four consciousness clusters. The four mean score are slightly different by a cluster, but those are not a significant difference. It was shown that there is elongation similar to all consciousness clusters such as abilities or impression related to problem solving by the class practiced.

\subsection{On the relation between the frequency of activities that are perceived to be effective in improving abilities with the mean scores of recognition of technical terms and consciousness of abilities}

The correlation coefficient between the frequency of effective activities and recognition of technical terms is -0.32 . The correlation coefficient between the frequency of effective activities and the mean score of consciousness of abilities is -0.07 . The correlation coefficient between the recognition of technical terms and the mean score of consciousness of abilities is 0.30 . These three correlations are not significant. As a result, there are no correlations between the said variables. These three variables are independent of each other. It is thus clear that the frequency of effective activities is neither related to gaining of knowledge nor changes in consciousness. 


\section{Conclusion}

Some lessons in the module of Science II were delivered in the satoyama blended learning with a blend of three types of learning spaces and learning methods. Depending on the objectives of the lesson, three types of media (textbook, experts, ICT) were employed. The purpose of study is to establish the lesson contents for environmental education in the satoyama and to raise the learning effectiveness through BL-style lessons. To find out if the goals of the study were achieved, data on recognition of technical terms, confidence and desire in engaging in environmental education, consciousness of abilities and activities effective in improving abilities were collected from the participants. Various analyses were performed on the data, including cluster analysis, chi-squared test, significance testing and correlation analysis.

The new knowledge gained from the analysis of data is as below.

(1) Cluster 1 "Activities related to presentation in the classroom" are perceived to be effective in improving the scores of cluster I "Consciousness related to interest in and the satisfaction to activities" and cluster II "Consciousness of abilities related to listen and evaluate". Cluster 2 "Activities related to research and discussion" are perceived to be effective in improving the scores of cluster I "Consciousness related to interest in and satisfaction of activities". Cluster 3 on "Activities related to ICT use" is perceived to be effective in improving cluster III "Consciousness related to abilities to learn and explore" and cluster IV "Consciousness related to computer and abilities to present".

(2) The mean scores for each of the four clusters of perceived abilities increased on post-survey. There is no significant difference between the increases in score for each cluster.

(3) There is no correlation between frequency of activities perceived to be effective and recognition of technical terms. Likewise, there is no correlation between frequency of activities perceived to be effective and the mean score of consciousness in abilities. There is no correlation between the recognition of technical terms and the mean score of consciousness of abilities. The three variables mentioned here are independent of each other.

For this study, subjective data on how students perceive their own abilities are collected. Going forward, focus can be placed more on objective data that measures the increase in the competencies and abilities of the students. Tests on facts and comprehension can be conducted to collect objective data for analysis to complement the subjective data. Follow-up studies can also be done on the students to see their abilities in instruction as a teacher.

\section{References}

[1] Bersin, J. (2004) The blended learning book: Best practices, proven methodologies, and lessons learned, Pfeiffer, San Francisco, USA.

[2] Edsand, H., \& Broich, T. (2020) The impact of environmental education on environmental and renewable energy technology awareness: Empirical evidence from Colombia, International Journal of Science and Mathmatics Education, 18, pp.611-634. doi:10.1007/s10763-019-09988-x

[3] El-Batri, B., Alami, A., Zaki, M., \& Nafidi, Y. (2019) Extracurricular environmental activities in Moroccan middle schools: Opportunities and challenges to promoting effective environmental education, European Journal of Educational Research, 8(4), pp.1013-1028. https://doi.org/10.12973/eu-jer.8.4.1013

[4] Forestry Research Institute Kansai Branch (2009) Collaboration with forest study and the natural learning: A concept and activity example, pp.1-19.

[5] Fujimoto, Y., \& Miyaji, I. (2008) An Information Exchange Study on the Electronic Bulletin Board about Observation of Plants to Foster the Expression Ability Required to Communicate, Transactions of Japanese Society for Information and Systems in Education, 25(1), pp.54-63.

[6] Goldman, D., Assaraf, O. B. Z., \& Shaharabani, D. (2013) Influence of a non-formal environmental education program on junior high-school students' environmental literacy, International Journal of Science Education, 35(3), pp.515-545.

[7] Hasegawa, S., Niimura, M., Suzuki, H., Komatu, H., \& Fuwa, Y. (2016) Consideration of the early detection technique of the poor results person through characteristic analysis of the learning behavior, Japanese Society for Information and Systems in Education Research Report, 30(6), pp.41-48.

[8] Ida, H., \& Aoki, M. (2006) Outlook on nature familiar with teacher training college students and natural education depending on it, Japanese Journal of Conservation Ecology, 11(2), pp.105-114.

[9] Japanese National Commission for UNESCO, (2016) Education for sustainable development, Retrieved from http://www.mext.go.jp/unesco/004/1339957.htm.

[10] Maesako, Y. (2006) Nature activity in childcare centers and the education for natural environments in a professional training college, Nara Saho College Research Bulletin, (14), pp.63-81.

[11] Miyaji, I. (Ed.) (2009) Toward Blended Learning from E-learning, Kyoritu-Shuppan, Tokyo, Japan.

[12] Miyaji, I. (2013) Effects of Blended Class on "History of Computers" with Peer Assessment for an Assignment to 
Introduce a Historical Character, Journal of Modern Education Review, 3(10), pp.760-770.

[13] Miyaji, I., Fukui, H. (2020) Change in knowledge and awareness in teacher education on Satoyama environmental learning: Through a blend of learning spaces, methods and media, European Journal of Educational Research, 9(4), pp.1663-1674. https://doi.org/10.12973/eu-jer.9.4.1663

[14] Nakaguchi, K., \& Asada, H. (2016) Experience training which viewpoints mountain village and sea learning: For the learning which is cooperated with locality, Ishikawa Prefecture Education Center Research Bulletin, Nature in Ishikawa, No.40, pp.1-19.

[15] Natural Environment Bureau, Ministry of the Environment (2012) Results of "questionnaire on the promotion effect of the maintenance activity of satochi and satoyama", pp.1-30.

[16] Nozaki, K. (2012) Drafting of the river investigation training and the education effect in a childcare person and primary school teacher training course, Japanese Journal of Ecology, 62(1), pp.51-58.

[17] Okamoto, C., Takiuchi, R., Komatsu, T., et al. (2015) Effect of the support of mastering nursing technique using blended learning, Journal of Gifu Nursing Society, (7), pp.67-74.

[18] Thorne, K. (2003) Blended learning: How to integrate online \& traditional learning, Kogan Page, London, UK.

[19] Uyanik, G. (2016) Effect of environmental education based on transformational learning theory on perceptions towards environmental problems and permanency of learning, International Electronic Journal of Environmental Education, 6(2), pp.126-140.

[20] Uz, R., \& Uzun, A. (2018) The influence of blended learning environment on self-regulated and self-directed learning skills of learners, European Journal of Educational Research, 7(4), pp.877-886. https://doi.org/10.12973/eu-jer.7.4.877 